\title{
Editorial
}

\section{MOLECULAR MEDICINE MILESTONES}

\author{
David G. Nathan, M.D., President \\ Molecular Medicine Society and Dana Farber Cancer Institute
}

In January 1995, in an editorial in Molecular Medicine (1), I informed you of the birth of the international Molecular Medicine Society (MMS). Soon thereafter, Molecular Medicine became the official journal of the Society. Now, I am pleased to recount considerable progress during our inaugural year.

The number of those joining MMS is burgeoning, with a preponderance of distinguished scientists requesting fellowship status. We encourage everyone with an interest in molecular medicine to become a member of the Society. Please note that those in training-students, house-officers, and postdoctoral fellows-are eligible for a one-third discount on the membership fee.

From the inception of Molecular Medicine our contributing editor system (similar to that of the Proceedings of the National Academy of Sciences) has ensured publication of a steady stream of excellent articles. It was not surprising, therefore, that Molecular Medicine was rapidly incorporated in the major scientific and medical databases, including Current Contents and the Science Citation Index within five months of its premiere issue and MEDLINE within ten months. All decisions are made with dispatch and the time from receipt of manuscripts to publication in our first year of publication averaged only three and one-half months.

One of our highest priorities has been to organize the first annual Molecular Medicine Society meeting, and we began to plan it in conjunction with Science. When Floyd Bloom became the new editor of Science, he made the excellent decision to work with the three major clinical research societies, the Association of American Physicians (AAP), the American Society for Clinical Investigation (ASCI), and the American Federation for Clinical Research (AFCR), and MMS was accorded the honor of being included in their joint event Biomedicine '96. Floyd referred to this in a recent editorial entitled "Biomedicine '96: A new partnership" (2), "Leading off a long weekend of science will be a program organized by the relatively youthful Molecular Medicine Society." We have had immense cooperation from the Tri-Societies, with Arthur H. Rubenstein, President of AAP, writing, "I must say that I was excited both by the content of your meeting, as well as its proximity to that of the TriSociety meeting. I am optimistic that our societies will prosper and that these links will prove to be very important in unifying and enhancing our common scientific goals."

At a planning session for Biomedicine '96, there was great interest in the following unique aspects of our fledgling society:

MMS is global in scope, with distinguished regional vice presidents in Europe, Asia, Africa, and Latin America.

MMS membership includes basic scientists as well as clinical investigators, recognizes research accomplishments by granting fellowship status, and welcomes anyone with an interest in molecular medicine.

MMS focuses exclusively on the molecular level of pathogenesis and intervention, and via a common language and techniques, reintegrates medical research.

MMS, therefore, can bring to Biomedicine '96 plenary sessions unfettered by subspecialty and disciplinary barriers.

The Molecular Medicine Society will lead off the Tri-Society meeting on Friday afternoon May 3, 1996 at the Sheraton Washington Hotel with the following program: 
1:00-2:30 PM-Sponsored lunch for the first 100 members and fellows-to sign up fax: 516 869 8428. Featured will be the presentation of the Maclyn McCarty Prize for the best paper by a young investigator in Volume 1 of Molecular Medicine, and an address by Floyd E. Bloom, Scripps Research Institute and Editor of Science.

2:30-3:30 PM-Plenary 1-Discourse by Sir David Weatherall, Regius Professor of Medicine at $\mathrm{Ox}$ ford, and three papers selected from abstracts submitted to MMS.

3:30-4:00 PM-Refreshments.

4:00-5:00 PM-Plenary 2-Discourse by Richard A. Young, Whitehead Institute, and three selected papers.

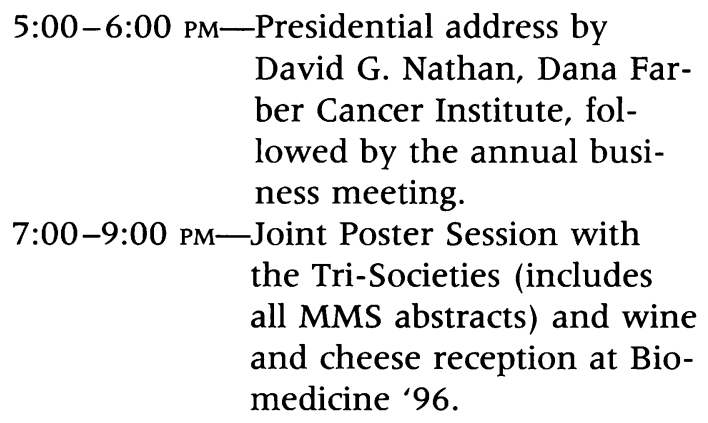

I trust the above will convince your and your colleagues to join the Molecular Medicine Society, publish in Molecular Medicine, and participate with the Tri-Societies, Science, and MMS at Biomedicine' 96.

\section{REFERENCE}

1. Nathan DG. (1995) Mol Med 1: 119. Editorial.

2. Bloom FE. (1995) Biomedicine '96: A new partnership. Science 270: 1279. 